\title{
The strategy versus the direct-response method: a first survey of experimental comparisons
}

\author{
Jordi Brandts • Gary Charness
}

Received: 9 November 2009 / Accepted: 11 January 2011 / Published online: 21 January 2011

(C) The Author(s) 2011. This article is published with open access at Springerlink.com

\begin{abstract}
In this paper, we present a first survey of the literature regarding whether the strategy method, in which a responder makes conditional decisions for each possible information set, leads to different experimental results than does the more standard direct-response method, in which the responder learns the action of the first mover and then chooses a response. Of the twenty-nine existing comparisons, sixteen find no difference, while four do find differences, and nine comparisons find mixed evidence. We also find some indications about the underlying determinants of when the two methods lead to different responses. For example, it appears that levels of punishment are substantially lower with the strategy method. In addition, it also appears that difference across these elicitation methods are more likely when people make fewer contingent choices. Finally, in no case do we find that a treatment effect found with the strategy method is not observed with the direct-response method.
\end{abstract}

Keywords Strategy method $\cdot$ Experiments $\cdot$ Elicitation $\cdot$ Framing

JEL Classification B49 · C90 • C91 • C92 · C79

\section{Introduction}

We present a survey of experimental studies that compares behavior under two different methods of eliciting decisions: what we shall call the direct-response method,

\footnotetext{
J. Brandts

Department of Business Economics, U. Autònoma de Barcelona and Institut d'Anàlisi Econòmica, CSIC, Campus UAB, 08193 Bellaterra, Spain

e-mail: jordi.brandts@uab.es

G. Charness $(\varangle)$

Department of Economics, 3051 North Hall, University of California, Santa Barbara, CA

93106-9210, USA

e-mail: charness@econ.ucsb.edu
} 
in which subjects make decisions whenever it is their time to do so, and the strategy method, in which subjects make contingent decisions for all nodes at which they may have to play. A priori it is possible that these two methods lead to different behavior, but whether this presumption is accurate is an empirical question. In this paper we present those studies that carry out a direct comparison of behavior between the two methods and discuss the overall implications of this literature.

The strategy method is potentially very useful for gathering experimental data, since one obtains observations even at nodes that are only reached occasionally in the actual course of play. An example from Charness and Rabin (2002) illustrates this point: A first mover can choose between passing the decision to the responder or choosing an outside option in which both the first mover and the responder receive 550 payoff units; if the decision is passed, the responder chooses between (First mover, Responder) payoffs of $(750,375)$ or $(400,400)$. There were 66 pairs who played this game, but only five first-movers chose to pass the decision. If the directresponse method had been used, only the data for these five observations would have been gathered; of course, the strategy method yielded 66 observations. Obviously, there are more observations with the strategy method, but the issue of whether these observations resemble those gathered with direct response is unresolved. ${ }^{1}$

According to the standard game-theoretic view, the strategy method should yield the same decisions as the procedure involving only observed actions. It could, however, be criticized on the behavioral grounds that its hypothetical character makes it too psychologically cold to be realistic as an abstraction of the natural setting. Roth (1995) presents a short discussion of the potentially relevant issues, pointing out on p. 323 that "having to submit entire strategies forces subjects to think about each information set in a different way than if they could primarily concentrate on those information sets that arise in the course of the game." 2

It is worthwhile to briefly refer to the history of the strategy method. In a seminal article Selten (1967) introduced a method (which he called the "strategy-method") to elicit decisions in an experiment. This strategy-method was meant as an improvement over an older method, the so-called "protocol-method", in which subjects made decisions in the direct-response mode, but were also required to write down the reasons for every choice they made. These reasons were then classified and a distribution of these reasons was used to get a coarse picture of observed decision-processes. However, the protocol-method was found to have a number of drawbacks, and Selten (1967) proposed a method involving the use of strategies. This Selten strategymethod consists of two parts. First subjects become familiar with the environment

\footnotetext{
${ }^{1}$ Another approach to gathering data at nodes that are only occasionally reached is to simply tell the responder that the first mover has made a particular choice, even if this is not the case. However, the use of deception is verboten in experimental economics, and is another topic entirely.

${ }^{2}$ In addition to the issue of the strategy method versus direct response, there are other important presentation issues in experimental economics. Some of the main dimensions in which the presentation can vary are with respect to the magnitude of monetary stakes, the use of a more or less descriptive context, the manner by which subjects have the opportunity to learn about the situation, whether people play a oneshot game or whether this game is repeated with random re-matching, whether information is presented in matrix form or as a decision tree, and whether two players rotate roles in two separate plays of the game. See the working paper Brandts and Charness (2009) for more discussion.
} 
through playing with the direct-response method. Then, after acquiring a good understanding of the situation, subjects independently formulate a complete strategy for a game, which could then be discussed with the experimenters and subsequently modified as the experiment progressed. ${ }^{3}$

The general idea behind the Selten strategy-method was both to elicit thoughtful behavior from subjects and to gain insights into the cognitive processes behind decisions. What we call the strategy method (a term which, to the best of our knowledge, was first used in Mitzkewitz and Nagel 1993) is a simpler variant of the original strategy-method, where subjects are only asked to submit contingent decisions for a number of decision-nodes. The method has most often been used for simple games for which subjects are asked to give a complete strategy, but in some more complex games partial strategies are also sometimes elicited. The strategy method makes it possible to get at some of the potential virtues of Selten's strategy-method in a simpler way. It may lead subjects to make more thoughtful decisions and, through the analysis of a complete strategy, may lead to better insights into the motives and thought-processes underlying subjects' decisions. At the same time it allows for a more economical data-collection process. ${ }^{4}$

The laboratory makes it possible to directly study the implications of different forms of elicitation, and here we focus on one of the relevant dimensions: the effects of the strategy method. ${ }^{5}$ We start by documenting the extent to which the use of the strategy method leads to different behavior than the direct-response method. In our discussion section we also present some considerations of the factors that may lead to different behavior under the two elicitation methods. ${ }^{6}$

We have structured our paper as follows. Section 2 consists of summaries of studies that compare behavior using these two approaches, as well as some studies on related elicitation issues; we also include a summary table that provides an overview of all the studies surveyed in this paper. In Sect. 3 we provide a discussion of the evidence and categorize the studies across five dimensions. In Sect. 4 we briefly present some studies that deal with some related elicitation issues. We conclude in Sect. 5 .

\footnotetext{
${ }^{3}$ Note that under Selten's a method subjects decide under the direct response and the strategy method in sequence (rather than in comparison) as part of a way of familiarizing themselves with the environment. Some papers that use the Selten-method include Axelrod (1984), Keser (1993), Selten et al. (1997, 2003).

${ }^{4}$ However, the original Selten strategy-method is still superior if one is interested in a detailed analysis of mental models, motives and expectations.

${ }^{5}$ We certainly do not wish to imply that no previous researchers have examined this issue. For example, Amnon Rapoport and co-authors examined this question in a series of experiments in the 1990's, while Oosterbeek et al. (2004) provide a meta-analysis of ultimatum-game experiments, with one focus on the strategy method. Krawczyk (2006) also presents a summary of past results on the strategy method, while also providing a theoretical discussion and model within the framework of psychological games. Our contribution is to look specifically at all studies (that we could find at the time of writing) that provide direct evidence on this issue, typically by conducting treatments with both direct response and the strategy method within the same study.

${ }^{6}$ For a new analysis of a variety of procedural issues in experimental economics, see Bardsley et al. (2010).
} 


\section{Literature review}

In this section, we review previous experimental evidence that directly compares behavior across the strategy and direct-response methods. We first describe experimental work that shows a difference in behavior, follow this with a description of experimental work for which the evidence could be argued either way, and then present evidence from papers that show no difference across these elicitation methods. Our descriptions are quite straightforward, since we only want to inform the reader about the content of the study and not provide an analysis of the papers. Within each set of papers the order of presentation is chronological. For each of the three sets of papers, we present the results of simple tests for differences across the two methods. ${ }^{7}$ At the end of Sect. 2 we present, for easy reference, a summary table of all the studies we describe.

Our way of classifying the literature may appear to be rather crude to some readers. However, any classification by type of game or some similar criterion based on the content of the studies is very hard at this point, since the number of existing studies is rather limited. Nevertheless, in the discussion section we do provide some thoughts on possible differences for different kinds of games.

\subsection{Experiments that found a difference}

Brandts and Charness (2003) had subjects play a game in which one player sent a signal indicating the intent to choose an action that was favorable to the other player or to choose an action that was unfavorable to the other player; after the message was sent and received, the players then made simultaneous binary choices. The second player could punish (reward) the first player at a cost if the outcome was unfavorable (favorable) to him. In one case, the second mover made a contingent choice of punishment (reward), which was in effect if and only if the first player actually chose the unfavorable action. In the other case, the second player observed the first-player's choice before choosing whether to punish. In both cases the combination of a deceptive message and an unfavorable choice was punished at about twice the rate as was an accurate message and an unfavorable choice, but the levels of the punishment rates were roughly double when the direct-response method was used. ${ }^{8}$ Thus, while the treatment effect found with the strategy method was still present with the direct-response method, the overall levels of punishment were significantly different ( $Z=1.83, p=0.034$ and $Z=2.10, p=0.018$, respectively, both one-tailed tests of the hypothesis that deception leads to more punishment); the reward rate was slightly higher with direct response than with the strategy method $(23.1 \%$ versus $17.1 \%$, but this difference is not statistically significant $(Z=0.95)$.

\footnotetext{
${ }^{7}$ We realize that this is a rather crude way of statistically analyzing the evidence. One limitation of the procedure we use is that the different studies in a sense are not independent from one another, since some deal with very similar topics (e.g., they study variants of a particular game like the ultimatum game), while other studies deal with very different issues. However, we feel that our simple tests are a useful tool for getting an impression about the existence of differences between the two elicitation methods.

${ }^{8}$ The punishment rates with and without deception and with the strategy method were $28 \%$ and $12 \%$, while these rates were $56 \%$ and $27 \%$ with the direct-response method.
} 
Brosig et al. (2003) used two games, one with low-punishment cost and one with high-punishment cost, in which they tested behavior with both the strategy and the direct-response methods. ${ }^{9}$ In the game with low-cost punishment, there is more selfish behavior by first movers with direct response, with marginal statistical significance. There is no significant difference across elicitation method in the responder's rate of rewarding (at an expensive rate) the first mover for a generous choice. However, there is a startling difference in the low-cost punishment rates after a selfish first-mover choice- $42 \%$ in the "hot" condition and $0 \%$ in the "cold" condition! In the game with high-cost punishment, once again first movers are more selfish to a marginally-significant degree; however, there are no substantial or significant differences in responder behavior across elicitation method, perhaps because it is so expensive to either reward or punish that little of either is observed.

Murphy et al. (2007) have subjects play a game that is a form of trust dilemma. There are three people in a group, and each person can stop the game in continuous time (up to 45 seconds in a period). The payoff grows over time, but each person has an incentive to be the one who ends the game. The paper compares results from Murphy et al. (2006), which used the strategy method, to results with a comparable treatment using the direct-response method. ${ }^{10}$ First, there is more cooperation in the direct-response treatment late in the session; a comparison of the mean payoff for the last 30 rounds in each game by a $t$-test gives $t=6.25, p<0.001$. Second, the dispersion in the winning stopping times within a round was higher in the directresponse treatment $(t=-4.91, p<0.001)$.

Casari and Cason (2009) use a simplified trust game, where the first-mover could either pass his entire endowment (each person is endowed with 10 units) or nothing; if the endowment was passed, the responder received 50. In the strategy method, the responder made contingent return choices in $[0,60]$ for the two possible cases, while with direct response the responder learnt the first-mover's choice. While there is no significant difference in first-mover behavior across elicitation methods, the mean amount returned was 12.6 with direct response, compared to 7.4 with the strategy method ( $Z=2.22, p=0.026$, two-tailed test). Similarly, the proportion of responders who return nothing is $50 \%$ higher with the strategy method ( $p=0.043$ ), while the proportion of responders who return half of the available surplus is more than triple with direct response $(p=0.019)$.

\footnotetext{
${ }^{9}$ The game was played sequentially, the first mover chose A or B, and the responder then chose 1 or 2 . The payoffs (in DM) in the low-cost punishment game were $(4,20)$ in the A1 cell, $(12,12)$ in the A2 cell, $(-4,5)$ in the B1 cell, and $(10,7)$ in the B2 cell; in the high-punishment game the " 5 " in the B1 cell is replaced by a " 0 ". Thus, while A2 Pareto-dominates B2, the latter is the equilibrium (with standard preferences). The responder can exploit a choice of A by choosing 1, and can also punish a B move at a cost of either 2 or 7 units.

${ }^{10}$ In the earlier (later) paper there were 90 (60) rounds, with random and anonymous re-matching every round in both studies; thus, periods 31-60 in one study are being compared to periods $61-90$ in the other study. Nevertheless, the authors state in footnote 3: "We have no reason to suspect that the results under the strategy method would have been different if it were to be played for 30 more rounds."
} 


\subsection{Studies with mixed results}

Rapoport and Fuller (1995) conduct an experiment using the sealed-bid doubleauction mechanism. Each buyer and seller blindly drew an envelope from a set of envelopes numbered from 0 to 100; this envelope determined the value and the cost, respectively. Each player then chose a bid, with trade possible if the buyer's bid was at least as high as the seller's bid (offer); in this case, trade took place at the average of the bids. In the first phase, people play 25 rounds with random re-matching within groups of 10, maintaining the same role throughout the experiment, learning the results after each round. In the second phase, each subject was asked to list bids, one for each of 25 possible values $(3,7,11, \ldots, 99) .{ }^{11}$ The second experiment was identical, except that the envelopes were number from 0 to 200 , and the 25 possible values were from $(6,14,22, \ldots, 198)$. In the case of the actual bids in the 25 periods of play and the strategies chosen for the 25 possible values, a bid function is estimated. It is found that "the individual bid functions elicited by the strategy method are positively and significantly correlated with the individual bid functions inferred indirectly from the actual bids." 12 However, the bid functions that are derived from the strategy method violate monotonicity less often.

Seale and Rapoport (2000) used a market entry game, with three sets of parameters and 50 periods. They use the Selten-style form of the strategy method, in which the interacting agents are first exposed to a repeated play of the game to provide them some experience, and then specify complete strategies of play. Rather than using a within-subject comparison (the paper asserts that within-subject tests can be problematic owing to a dissipation of spontaneity), the results in this paper are compared with the results in two papers that used direct response, Sundali et al. (1995) and Rapoport et al. (1998). Little difference in aggregate behavior is found across the elicitation methods, as the mean number of entries does not differ across methods for a large number of values for the capacity of the market. Only one of the $30 t$-tests across comparisons indicates statistical significance, and this is when the capacity constraint is an extreme value. However, with respect to having a clear cutoff number for when to enter the market, individual behavior differs across elicitation methods. So it is entirely possible that while the strategy method and direct response lead to differences in individual behavior, there may be no difference with aggregated results. In such a case, the question is which results are germane.

Güth et al. (2001) use three mini-ultimatum games in which they vary whether an exactly even split or a nearly equal split is an available choice, finding that behavior is sensitive to slight differences in unchosen alternatives. ${ }^{13}$ Regarding the effects of elicitation methods, proposers in the case of direct response are substantially more likely to make the 'fair' choice if an exactly equal split is possible than when only

\footnotetext{
${ }^{11}$ There was also a second experiment, which was identical to the first, except that the envelopes were numbered from 0 to 200 , and the 25 possible values were from $(6,14,22, \ldots, 198)$.

${ }^{12}$ In three of the four cases (two experiments $\times$ two roles), three of the four correlations are greater than 0.85 .

${ }^{13}$ However, there is a slight confound in that the timing (sequential or simultaneous) in these games were different across the strategy and direct-response methods; see p. 165 of the published article.
} 
a nearly-equal division is possible; responders are also marginally less likely to reject 'unfair' choices when either a lopsided or a nearly-equal split is possible than when the proposer choice is between lopsided and an exactly even split. However, the latter treatment effect is not present when the strategy method is used. Nevertheless, perhaps because the number of observations with the strategy method is small, it is unclear that the strategy method leads to different behavior than does direct response, as there are no significant differences in proposer or responder behavior for any pairwise comparison. ${ }^{14}$

Meidinger et al. (1999) focus on players' coordination in the investment game. In a one-shot investment game with an endowment of 50 for each player, the average amount sent is 30.5 in the strategy-method treatment and 30.0 in the direct-response treatment. Eight of 19 responders are classified as cooperative with direct response, compared to five of 19 with the strategy method $(Z=1.03)$. The amount sent is more bi-modal (either 0 or 50) in the direct-response treatment; the difference at 50 alone or at both poles is marginally significant ( $Z=1.59$ or 1.71 , respectively). The authors argue that there is a difference across elicitation methods, ${ }^{15}$ but this seems a bit less than conclusive.

Offerman et al. (2001) used an overlapping generations game, in which subjects both make a choice and formulate a strategy to play the game. People make one binary choice in a game where cooperation is feasible ${ }^{16}$ this choice is matched with the choice of the next generation; there is also a "recommendation" treatment, in which people are provided with a recommendation (a grim-trigger strategy) supporting the cooperative equilibrium. Since actual choice data and strategies are available for each participant, it is possible to check for differences between actual choices and the submitted strategies. In the baseline treatment, three of 31 choices $(9.7 \%)$ are inconsistent with what would have been prescribed by the submitted strategy. However, the level of inconsistency is considerably higher in the recommendation treatment, where eight of 30 choices $(26.7 \%)$ are inconsistent with the strategy. Differences typically reflect a participant selecting the recommended strategy, but relenting from the grim-trigger strategy and playing cooperatively when the strategy called for defection. $^{17}$

\footnotetext{
${ }^{14}$ With respect to 24 feasible pairwise comparisons (including pooled data), no difference in behavior is significant at the $10 \%$ level on a two-tailed test. Further detail is available upon request.

${ }^{15}$ They write: "Pour la coopération, il n'est donc pas indifférent qu'un jeu soit joué de manière séquentielle ou simultanée. La comparaison des traitements SEQ et SIM a montré que, selon le traitement, des différences de comportement sont décelables, imputables pour une part à des stratégies de manipulation par les émotions."

${ }^{16}$ In this game, if both the current player and her successor choose A, the current player receives 50 . A then B leads to a payoff of 15 , B then A leads to 70 , and B then B leads to 30 . Thus, A is a dominated strategy under standard preferences, but the (A, A) outcome Pareto-dominates the (B, B) outcome.

${ }^{17}$ We call the reader's attention to the fact that in this study, together with some others discussed below, subjects are allowed to revise their decisions. This specific design feature may have a separate effect on behavior, since behavior both under the strategy method (as choices do not count) and under direct-response (as anchoring may make it difficult to change behavior) may be influenced. We thank an anonymous reviewer for pointing this out. Table 2 in the online Appendix mentions which studies have this characteristic.
} 
Kübler and Müller (2002) investigate duopoly markets with price competition and either random re-matching or fixed matching; we consider their treatments with sequential play. ${ }^{18}$ With the strategy method, in each of the 15 rounds the first mover had to specify a single price, whereas the second mover was asked to name a price for each of the possible prices of the first mover; with direct response, second movers submitted their prices after observing the first mover's decision. There is little difference in behavior under the random-matching protocol, as the median prices are the same and the mean prices differ only slightly for strategy-method sequential play and truly sequential play. However, under fixed matching the median price differs for the first mover, and the average price is about $23 \%$ lower with truly sequential play (all results taken from Table 2 in their paper).

Oxoby and McLeish (2004) perform an explicit test of the strategy and directresponse methods in the ultimatum game. The mean offer was 3.84 (out of 10) with the strategy method, compared to 3.74 with direct response; the mean acceptance rate was $81.5 \%$ (76.7\%) with the strategy method (direct response). ${ }^{19}$ However, their Fig. 2 suggests that there are differences in rejection behavior with small offers: when an offer of three is made, slightly more than $10 \%$ (50\%) accept the proposal with direct response (strategy method); the comparison is $0 \%$ versus $39 \%$ when the offer is two, and $0 \%$ versus $37 \%$ when the offer is one. Although the data needed for statistical tests are not presented, these differences seem large.

Falk et al. (2005) conducted prisoner's dilemma experiments with sanctioning opportunities. Each participant (in groups of three) was informed about the other two players' individual decisions, and could then punish the other players by assigning them deduction points. The punishment pattern with direct response is qualitatively similar to that observed with the strategy method. However, even though the percentages of cooperators who punish is similar under both methods, the level of cooperators' sanctions of defectors is nearly twice as high with direct response as with the strategy method (Mann-Whitney test, $p=0.018$ ). Thus, the overall results seem mixed with respect to the effect of the strategy method versus direct response, with qualitative similarities and quantitative differences.

Cox and Hall (2010) conducted real-effort experiments with common-property trust games and private-property trust games, using strategy-method play or sequential play (direct response). In the first case, the common property was described as "joint decision fund" from which both people in a pair can withdraw. The first mover can withdraw an amount from the joint fund and place it into his private fund; each unit withdrawn by the first mover reduces the joint fund by three units. The secondmover's decision is how to divide the remaining joint fund between her private fund and the paired first-mover's private fund after the first-mover's decision. The privateproperty trust game was the same as the standard trust (investment) game, except that the second mover could also send any portion of her original endowment. They found that the conclusions that they reach about the private-property vs. common-property

\footnotetext{
${ }^{18}$ There were also treatments conducted with simultaneous play, but the best comparison would seem to be across the treatments with sequential play.

${ }^{19}$ Wilcoxon tests find no difference in the distribution of offers across treatments $(p=0.47)$, and there is no difference $(p>0.60)$ in the distribution of acceptance rates when the entire distribution is considered.
} 
treatment comparisons with strategy data or sequential-play data depend on the type of statistical test applied to the data. With some tests for differences across property regimes, these two data sets led to the same conclusions, but not so with other tests. Cox and Hall attribute this difference to "missing observations" with sequential-play data.

\subsection{Studies finding no difference}

Mitzkewitz and Nagel (1993) use the strategy method in an offer game and in a demand game in which the pie size of $\{1, \ldots, 6\}$ was determined by a role of a die and is unknown to the responder. The first mover made an offer (demand) from $\{0,0.5,1, \ldots, 6\}$ and the responder stated contingent acceptance or rejection for each possible offer (demand); there were eight rounds with random, anonymous re-matching, but no role change. Rapoport and Sundali (1996) and Rapoport et al. (1996) provide comparison to the offer (demand) game using direct response. In their designs, there are 101 pie values. The first mover observed the pie value, and then specified a division of the pie; the responder learned the offer (demand) and then accepted or rejected. The two studies report little overall difference between their results and those of Mitzkewitz and Nagel (1993), although they caution that the comparison is problematic due to other differences between the two studies.

Cason and Mui (1998) examine behavior in a sequential dictator game, wherein people allocate $\$ 40$ (with buyer-seller framing, and with the buyer constrained to buy at the price selected) before and after learning the allocation made by one other subject in the relevant-information condition. Roles were drawn randomly and could switch in these two decisions (50\% likelihood). For the strategy method, participants received no information between their two price decisions. After submitting their first price, a subject filled out a second form specifying a complete price-choice strategy contingent on all 21 possible first-choice prices selected by the subject with whom he was randomly paired. Comparisons were made between the first-price choices in both treatments, as well as between the second-price choices in the relevant-information treatment and the realized second-price choices with the strategy method. The authors state: "In no cases are the distributions, means, or fraction of subjects ... significantly different, so we conclude that use of the Strategy Method in this setting does not significantly alter choices."

Bosch-Domènech and Silvestre $(1999,2006)$ investigate whether or not participants would like to insure their experimental wealth. There are seven different wealth levels with which participants could be endowed. Each person first made contingent insurance choices for each randomly-drawn possible endowment; he or she then learned of the actual endowment and then had an opportunity to change the contingent choice that had been made. In fact, only two of 63 people made a change. It would appear that there is no difference between behavior between the strategy method and direct response, although it might simply indicate that participants don't like to change their minds.

Brandts and Charness (2000) specifically set out to test the direct-response method versus the strategy method with simple games, Prisoner's Dilemma and Chicken. With direct-response, a first mover made a choice that was observed by the responder, who then chose a response. With the strategy method, the responder made two 
contingent choices, one for each possible first-mover choice. In no case was a positive or negative response close to being significantly different $(p=0.57,0.26$, and 0.77 for the three comparisons) across the strategy and direct-response methods; in addition, no first-mover choice differed across elicitation methods ( $p=0.35$ and 0.79 for the two comparisons).

Sonnemans (2000) tests the strategy method using a sequential search problem and an individual decision-making problem. A participant can sell an "article" to the computer, which makes an initial bid. Additional bids (drawn from a uniform discrete distribution) can be obtained from the computer at a cost, and the participant can at any time decide to sell the article for the highest bid so far. In each period people first made decisions (requested as many bids as they liked), and then their strategy operated on the same sequence determined. They could change their strategy after each of the 20 periods. One of the two decisions (randomly drawn) in each period was (randomly) chosen for payment. Of 31 subjects, 20 never changed their strategy at all over 20 periods, and seven only changed some numbers (but not the form of the strategy). The decisions made by the individual sequentially ("by hand") in the period equal the decisions by the strategy in $91.8 \%$ of the cases.

Armentier (2004) used a version of the ultimatum game, in which the responder first chooses a cut-off value for acceptance (the minimum acceptable offer) and then has an opportunity to revise his decision after seeing the offer. Any such revision had only a $50 \%$ chance of being accepted by the computer, giving the responders an incentive to take their specification of the minimal acceptable offer seriously. Responders revise their strategies only $5.9 \%$ of the time. Most revisions $(51.6 \%)$ took place in the first 10 periods (of 60 rounds with 60 subjects in two sessions). By far, the most frequent revisions occur when the offer is just below the minimum acceptable offer.

Hommes et al. (2005) conduct a classroom experiment, in which participants submit a complete forecasting strategy in a dynamic asset pricing game; this takes place in four rounds over an eight-week period. There was an introductory experiment, in which a pension fund has to decide how much to put in the bank and how much into stocks, needs an accurate prediction of the stock price). Students participated for 50 periods in each of two different markets. In a subsequent strategy experiment, people had to submit a strategy. Then, after they submitted strategies for the final round of the strategy experiment (but before receiving results), they were in a final lab experiment. In this final experiment, they could update and change their prediction behavior. The correlation between the predictions of the strategy and the predictions of the participants (in the final experiment) is high, averaging 0.85 (see their Table 7). They state: "In summary, the final experiment indicates that in general the strategies give a reasonably good description of the prediction behavior of the participants."

Falk and Kosfeld (2006) investigate a principal-agent game in which the principal can control the agent by choosing a minimum-performance requirement before the agent makes a choice. Direct response is used in most treatments, but the strategy method is used in a control treatment. Principals first choose whether or not to implement a minimum-performance requirement; each agent then learns the paired principal's choice before making a decision. The results show little if any effect across elicitation methods. The average (median) choice of an agent is 23.6 (20) if the principal does not exert control in the direct-response treatment; this compares to 23.0 (20) 
with the strategy method (Mann-Whitney test, $p=0.822$ ). If the principal chooses to exert control, the average (median) is 19.6 (10.5) with direct response, compared to 17.5 (10) with the strategy method (Mann-Whitney test, $p=0.589$ for the averages).

Fischbacher and Gächter (2006) consider a version of the public-goods game. In one treatment, participants chose how much to contribute for each average contribution level of other group members (groups of four). With the strategy method, people made two decisions, one was as an "unconditional contribution" and for the other they filled out a contribution table ( 21 values). One of the four people in the group was randomly selected to be the conditional contributor and the others contributed their unconditional contributions. With direct response, people make actual contribution decisions. Both cases took place in each session, with 10 periods for each; the order of the elicitation method was varied. "Strikingly, we ... find that the mean contributions in the [variants] are almost identical... Most individuals are consistent (not more than 2 tokens difference) in 7 or more periods out of 10 . There is a high degree of consistency between expressed preferences and actual contribution behavior for all distinct preference types."

Armentier and Treich (2007) use a first-price independent private-values auction (similar to the one used, with direct response, in Goeree et al. 2002). Two players participate in a sealed bid independent private-values auction (15 rounds), making a conditional sealed (integer) bid for each of five values. The prize awarded to the high bidder, who pays the price he or she has bid. Players are also asked to predict their own probability of winning the auction for a given list of bids, and values are then determined. The authors state that the relevant auction outcomes are both qualitatively and quantitatively consistent with those in Goeree et al. (2002). Statistical analysis offers no evidence that bidding behavior is significantly different across the two experiments, so that "implementing the auction in strategic form, and eliciting beliefs with a prediction contest do not appear to have introduced any significant treatment effect."

Büchner et al. (2007) use a version of the solidarity game of Selten and Ockenfels (1998). In a replication of the original game, the strategy method is used. Each of three participants has an independent two-thirds probability of winning a fixed amount of money and a one-third probability of ending up with nothing. Before knowing the result of the random draw, each participant makes a contingent choice of money to give to each loser if he or she turns out to be a winner and is matched with one or two losers. In a second treatment, they introduce a partial-play method, in which the participants know before deciding whether they are winners or losers, and only the winners decide how much they are willing to give to one or two possible losers in the group. One might expect the knowledge of being a winner or loser could reduce the sense of solidarity. However, Table 2 shows that there is no difference across treatments regarding the gifts to losers. The authors conclude: "Our results strengthen the view of no influence of the strategy method on behavior, similar to Brandts and Charness (2000) and others. The strategy method appears to be an innocent tool to study gift-giving behavior."

Fong et al. (2007) use a form of a one-shot trust game, wherein the first mover can keep or pass a "coupon". A kept coupon is worth either zero or four, with equal probability, while a passed coupon is worth six to the responder. The responder can 
send back up to four units, with each doubled for the first mover. Each responder was asked to formulate a strategy for each of three cases: the coupon was kept, the coupon was sent and was worth zero, and the coupon was sent and was worth four. After she constructed her strategy, she was told the value of the coupon if and only if the coupon was passed to her. After learning the first mover's choice, the responder was reminded of the choice planned for this case, and could then revise the choice at a small cost ( $4 \%$ of the endowment). Only $15 \%$ of responders (12 of 80 people) changed their decision, with half increasing the amount returned and half decreasing this amount The authors conclude: "The strategy method did not systematically bias subjects' choices," since a $15 \%$ error rate is not unusual, based on the Harless and Camerer (1994) estimate of a natural error rate of 15-25\%.

Solnick (2007) used an investment game done using four different experimental methods: (1) subjects exchange actual dollar bills, (2) subjects exchange play money to be converted later, (3) first movers write down how much they wish to send and responders make a choice after seeing this, and (4) the same as the third method, but responders instead make contingent choices for each of the 11 possible sent amounts $(\$ 0, \ldots, \$ 10)$. First movers send roughly the same amount in all conditions, with the amount sent with written messages and direct response about $9 \%$ lower than with written messages and the strategy method. Responders return a much smaller percentage (less when half) when actual cash is exchanged, but there is almost no difference for the written-message treatments: $29.6 \%$ with direct response and $30.8 \%$ with the strategy method. ${ }^{20}$

Muller et al. (2008) uses a two-stage voluntary-contribution mechanisms. Participants played a sequence of five two-stage games, with a strangers matching). In the strategy-method version, each person submits a contribution in stage 1 and also specifies a contingent contribution; stage- 1 contributions are then matched up in 3-person groups, thus (in combination with the stated strategies) determining the contributions in stage 2. In the direct-response version, people chose contributions in stage 1, and they then observed the total contributions in the group before making a choice in stage 2. Participants contribute $41 \%$ in stage 1 and $23 \%$ in stage 2 with the strategy method. With direct response, the corresponding figures are $37 \%$ and $23 \%$. There are clearly no significant differences for either comparison, although the pattern of deterioration over time is considerably smoother with submitted strategies.

Reuben and Suetens (2008) feature a repeated sequential prisoner's dilemma with a known probabilistic end. With the strategy method, people condition decisions on whether the period they are playing is the final round and whether the other player cooperates. There were two control treatments: (1) people are told whether it is the last period, and second movers still submit separate choices for whether or not the first mover cooperates, and (2) people are told whether it is the last period and each second mover also learns the paired first mover's choice. There is almost no difference in choices (see Fig. 3, p. 14), as the test of equality across the three treatments gives $p=0.992$ (and pairwise comparisons also show nothing close to any significant differences).

\footnotetext{
${ }^{20}$ While the paper points out some differences between the strategy method and the other methods when the amount sent was either $\$ 4$ or $\$ 9$, the comparison between the two written-message treatments involves only one and zero observations with direct response, so there is no basis for statistical comparison.
} 
Brandts et al. (2009) consider variations of a repeated (30 round) social-dilemma game. In the two treatments relevant to our paper, the first mover chooses whether to play either one of two other players, each of whom has a unique and identified ID. The first mover and the chosen person then play the game while the other person obtains a fixed payment and is not informed about the outcome of the interaction between the first mover and the chosen player. In the treatment corresponding to the strategy method, the two potential players make their choice before they knew whether they had been chosen. In the direct-response treatment, the chosen player is informed that he has been chosen before making a choice. There is no significant difference in cooperation levels, which were 6.71 (of 10) with the strategy method and 6.33 with direct response; there was also no significant difference in average per round earnings. ${ }^{21}$

For easy reference, Table 1 summarizes some of the information presented in Sects. 2.1-2.3; it describes the experimental task and presents a summary of the results for all papers.

\section{Discussion}

What can we conclude from the experimental literature on the strategy method? First, if one accepts our classification scheme, we see that there are four studies that find that the strategy method leads to different behavior than does the direct-response method. This compares to 16 studies that found no difference depending on the elicitation method, as well as nine studies with mixed results. The result of a simple binomial test comparing the frequency of there being a difference or not provides statistical support, with $Z=2.68$ and $p=0.007$, two-tailed test, readily rejecting randomness. $^{22}$ So there are significantly more studies that find no difference across elicitation methods than studies that find a difference.

One can nevertheless attempt to discern underlying determinants of when the strategy method leads to different results than does direct response. We would like to emphasize that our discussion here is preliminary, given the limited evidence and our lack of deep understanding of the issues at hand. A more careful analysis of these determinants will only become possible, once a more solid body of evidence has accumulated. However, at minimum the discussion below is a starting point for future studies. In the on-line appendix we present a summary table of the discussion in this section, where we classify all the studies with respect to the three issues discussed in this section, as well as according to whether choices could be revised or not.

One dimension of interest is whether the underlying game or decision involved emotions, since many people have speculated that the difference between a "hot" and a "cold" decision stems from the different degree of emotions present. ${ }^{23}$ In the 29

\footnotetext{
${ }^{21}$ Some additional evidence comes from comparing behavior in the moonlighting game in Falk et al. (2008), who use the strategy method, and in Abbink et al. (2000), who use direct response. The results are qualitatively similar.

${ }^{22}$ If we instead allocate half of the studies with mixed results to each of the two other categories, the binomial test gives $Z=2.23, p=0.026$, two-tailed test.

${ }^{23} \mathrm{~A}$ reviewer points out that there is a mild hypothesis-testing issue present, since the studies differ in many dimensions and in some cases may be significant by coincidence.
} 
Table 1 List of experiments testing for differences between strategy method and direct-response method

Author (year) Experimental task $\quad$ Summary of results

Studies finding a difference

Brandts and Charness (2003)

Brosig et al. (2003)

Casari and Cason (2009)

Murphy et al. (2006, 2007)

Studies with mixed results

Cox and Hall (2010)

Falk et al. (2005)

Güth et al. (2001)

Kübler and Müller (2002)

Meidinger et al. (1999)

Offerman et al. (2001)

(2004)
Punishment in $2 \times 2$ game

Punishment in $2 \times 2$ game

Simplified trust game

Trust dilemma with stopping time

Forms of trust game

PD experiments with sanctioning opportunities

Mini-ultimatum game

Duopoly markets with price competition

Trust game

Overlapping-generations cooperation game

Ultimatum game
Punishment rates double with direct response; treatment effect in both cases.

Punishment rate with low-cost punishment much higher with direct response; no significant difference with high-cost punishment.

Mean amount returned much higher with direct response; no significant difference in first-mover behavior

Across these two studies, more cooperative behavior and greater dispersion of winning stopping time with direct response.

In some treatments, there was no difference, while in others there was. Interestingly, whether they find treatment effects in their main design with the strategy or direct-response method depends on which statistical tests are used.

No qualitative difference in punishment patterns, but the level of cooperators' sanctions of defectors twice as high with direct response.

With direct response, responders marginally less likely to reject 'unfair' choices when lopsided or nearly-equal split is possible than when proposer choice is between lopsided and exactly even split; however, no treatment effect present with strategy method. But no significant differences in behavior for any pairwise comparison.

Little difference in behavior under the random-matching protocol, but average price under fixed matching is lower with direct response.

No difference in average amount sent, but amount sent is marginally more bi-modal with direct response.

Compares actual choices and submitted strategies. Small difference in baseline, larger difference in recommendation treatment.

No difference in mean offer or mean acceptance rate, but substantially fewer rejections of small offers with strategy method. 
Table 1 (Continued)

\begin{tabular}{lll}
\hline Author (year) & Experimental task & Summary of results \\
\hline $\begin{array}{l}\text { Rapoport and Fuller } \\
\text { (1995) }\end{array}$ & $\begin{array}{l}\text { Sealed-bid double auction } \\
\text { in pairs; random } \\
\text { value/cost }\end{array}$ & $\begin{array}{l}\text { Individual bid functions with strategy } \\
\text { method positively correlated with those } \\
\text { inferred from actual bids.; however, the bid } \\
\text { functions with the strategy method violate } \\
\text { monotonicity less often. }\end{array}$ \\
$\begin{array}{l}\text { Seale and Rapoport } \\
\text { (2000), Sundali et al. }\end{array}$ & Market-entry game \\
(1995), Rapoport et al. & $\begin{array}{l}\text { Little difference in aggregate behavior, but } \\
\text { "individual behavior is highly susceptible to } \\
\text { (1998) }\end{array}$ & $\begin{array}{l}\text { the details of the experimental procedure } \\
\text { and the method used for eliciting strategies } \\
\text { or decisions." }\end{array}$
\end{tabular}

Studies finding no difference

Armentier (2004)

Ultimatum game (MAO)

Armentier and Treich (2007), Goeree et al. (2002)

Bosch-Domènech and Silvestre (1999, 2006)

Brandts and Charness (2000)

Brandts et al. (2009)

Büchner et al. (2007)

Cason and Mui (1998)

Falk and Kosfeld (2006)

Fischbacher and Gächter (2006)

Fong et al. (2007)

Hommes et al. (2005)
First-price independent private-values auction

Insuring experimental endowments

PD and Chicken

Repeated social-dilemma game

Solidarity game

Sequential dictator game

Principal-agent (gift-exchange) game

Public-goods game

One-shot trust game

Forecasting in a dynamic asset pricing game
Responder first states contingent cutoff for acceptance, then sees offer. Can change after seeing offer, but did only $6 \%$ of the time.

Conditional bids qualitatively and quantitatively consistent with actual bids in other study.

People first made contingent choices and could change choice after learning actual endowment; only two of 63 people made a change.

In no case was response close to being significantly different; in addition, no first-mover choice differed across elicitation methods.

Almost no difference $(6 \%)$ in cooperation rates across methods.

No difference across strategy-method and partial-play treatments regarding the gifts to losers.

No findings of significant differences across strategy method and direct-response method.

Little difference across elicitation method in agent's choice, whether or not the principal chooses to exert control.

Unconditional and conditional choices made. Mean contributions almost identical, and individuals are highly consistent.

Responder could change contingent choice after learning first-mover's choice, but only $15 \%$ did so.

Could change submitted strategies in actual lab experiment. High correlation between predictions of strategy and actual predictions. 
Table 1 (Continued)

Author (year)

Experimental task

Offer/demand game with random pie size

(1993), Rapoport and

Sundali (1996), Rapoport et al. (1996)

Muller et al. (2008)

Reuben and Suetens (2008)

Solnick (2007)

Sonnemans (2000)
Sequential PD

Trust game

Sequential search problem
Summary of results

The two latter studies report little difference between their results and those of Mitzkewitz and Nagel (1993).

In first stage, contributions were $41 \%$ vs. $37 \%$; in second stage, contributions were $23 \%$ with both methods.

Virtually no difference in cooperation rates across methods.

Amounts sent $9 \%$ lower with direct response; amounts returned $4 \%$ less with direct response.

Participants first formulated strategy, then could change; decisions by hand equal the decisions by the strategy in $91.8 \%$ of the cases.

comparisons listed in Sect. 2, we consider that all but seven involved emotions. ${ }^{24}$ Of these seven comparisons, no difference was found in four cases, with mixed results in the other three. Four of the other 21 comparisons found differences, with mixed results in xis cases, and no differences in the other 12 cases. A Chi-square test finds that these distributions do not differ significantly $\chi_{2}^{2}=2.00, p=0.368$ ), so (perhaps surprisingly) there does not appear to be a clear differentiation on the basis of whether emotions are involved.

The influence of emotions could also affect a particular aspect of behavior. It may well be the case that punishment (or rejection) levels are lower when the strategy method is used, although there are only a few studies on this point. Regarding punishment Güth et al. (2001) find that unequal proposals are rejected $44 \%$ of the time with direct response, while these were rejected $30 \%$ of the time with the strategy method (pooled data from "all games" in their Table III). Brandts and Charness (2003) find that punishment rates double when direct response is used. Brosig et al. (2003) find a much higher punishment rate with direct response after a selfish play by the first mover. In Oxoby and McLeish (2004), small offers in a dictator game are rejected far more frequently with direct response. Falk et al. (2005) find that cooperators punish defectors almost twice as frequently when direct response is used than when the strategy method is used. While five studies are too few to make definitive statements, it is worth noting that the likelihood that the punishment with direct response is higher than with the strategy method in all five studies is only one in 32 .

\footnotetext{
${ }^{24}$ These seven comparisons are Armentier and Treich (2007), Bosch-Domènech and Silvestre (1999, 2006), Hommes et al. (2005), Kübler and Müller (2002), Rapoport and Fuller (1995), Seale and Rapoport (2000), and Sonnemans (2000).
} 
Thus, by this (one-tailed) binomial test, we can reject this pattern as being random at $p=0.031 .^{25}$

A second possible distinction is the number of alternatives that are available to the participant when the strategy method is used. In a sense, it seems more likely that one will be better able to imagine being in each alternative when there are fewer possibilities, that is, in a situation involving little complexity. Many studies have used binary designs, ${ }^{26}$ while others require participants to indicate strategies at a large number of contingent decision nodes. Thirteen of the 29 comparisons reviewed in this survey involved two options or fewer, while the other 16 involved three options or more. For the 13 comparisons involving fewer options, six found no difference, three had mixed results, and four found a difference. For the 16 comparisons involving more options, 10 found no difference, and six had mixed results. A Chi-square test shows the difference to be marginally significant $\left(\chi_{2}^{2}=5.38, p=0.068\right)$, while the test of proportions for whether a difference was found gives $Z=2.32, p=0.020$ (two-tailed test). On this basis, we cautiously conclude differences across elicitation methods are more likely when people make fewer contingent choices.

Another possible dimension is whether the decisions were made over multiple periods or in a one-shot game. Fifteen of the 29 comparisons involved one-shot games, while the other 14 did not. ${ }^{27}$ Overall, when the decision was one-shot, three comparisons found a difference, seven did not, and the other four had mixed results; when the decisions took place over multiple periods, one comparison found a difference, nine did not, and the other four had mixed results. While a chi-square test does not find a significant difference for these distributions $\left(\chi_{2}^{2}=1.25, p=0.535\right)$, it is nevertheless three times as likely that there will be a difference when the decision is only made once. So while the evidence is a bit scant, there is a suggestion that differences in behavior diminish over time. This result is in line with the general view that the influence of theoretically-irrelevant procedural details lose their influence once subjects have had enough experience to familiarize themselves with the environment. $^{28}$

Table 2 in the online Appendix categorizes all of the papers cited according to five characteristics: whether there is a difference between the two elicitation meth-

\footnotetext{
${ }^{25}$ The results are less clear regarding reward or cooperation, although they also go in the direction that there is more response with known play. We consider that perhaps six of the studies mentioned in our summary consider reward or cooperation: Cason and Mui (1998), Meidinger et al. (1999), Brandts and Charness (2003), Büchner et al. (2007), Muller et al. (2008), and Casari and Cason (2009). We see significantly more returned in Cason and Casari and slightly more reward with direct response in Brandts and Charness (2003). However, the other four studies find no difference.

${ }^{26}$ For example, Charness and Rabin (2002) conducted many response games where the would-be responder only had a choice after one of two first-mover choices; it was relatively easy to instruct a responder to make her choice on the assumption that the first mover had made the choice providing her with a relevant action, as her choice only mattered in this case.

${ }^{27}$ The one-shot treatments occurred in Bosch-Domènech and Silvestre (1999, 2006), Brandts and Charness (2000, 2003), Brosig et al. (2003), Büchner et al. (2007), Casari and Cason (2009), Cason and Mui (1998), Cox and Hall (2010), Falk et al. (2005), Falk and Kosfeld (2006), Fong et al. (2007), Güth et al. (2001), Meidinger et al. (1999), Oxoby and McLeish (2004), and Solnick (2007).

${ }^{28}$ This can be seen as evidence that there is considerable merit to Selten's proposed method of first gaining direct-response experience.
} 
ods, whether the experiment involved punishment, the number of choices involved, whether there were multiple periods and whether subjects could revise their choices.

Other issues have been mentioned in some of the papers reviewed, but the data here are few and even more insufficient to assess their impact than for the issues discussed above. For example, Brosig et al. (2003) suggest that a possible explanation for the difference between their results and those of Brandts and Charness (2000) is that in the latter paper each participant played the game twice, once as a first mover and once as a responder, rather than playing the game only once. The specific claim is that if participants play in both roles, "they are likely to undertake greater self-reflection from the beginning." This suggests that one must avoid cognitive dissonance, resulting in participants' decisions being "much more likely to be in line with each other." In other words, perhaps greater self-reflection cools one's emotions, so that there is little or no difference in behavior across elicitation methods.

Casari and Cason (2009) reflect on the differences between their results and those of Solnick (2007). One possible conjecture is that participants have better understanding of the task or game with direct response rather than the strategy method (although this would seem to apply more to complex games). Related to this point is that raising the stakes may reduce any such differences in the understanding of the task or game (the Solnick 2007 study used higher stakes). The authors also raise the issue of the greater number of decision nodes in Solnick (2007); this point is discussed above and seems relevant. Finally, Casari and Cason conjecture that the 'temperature' matters; while this seems eminently reasonable, we do not find support for it per se.

In closing this section, we feel that laboratory experiments are particularly effective at identifying treatment effects. In this sense, it is particularly important to know whether treatment effects found with one elicitation method also manifest with the other. At least one study (Güth et al. 2001) finds a treatment effect with direct response that is not present with the strategy method. On the other hand, Brandts and Charness (2003) find that while the punishment levels are much higher with direct response, the treatment effect that deception triggers more punishment is found with both the strategy and the direct-response methods. We are not aware of any instance where a treatment effect found using the strategy method was not also found with direct responses. If this observation is robust, it would mean that the strategy method provides a lower bound for testing for treatment effects.

\section{Studies on related elicitation issues}

The three issues that we discuss in Sect. 4 are rather closely related to the central issue of the paper. The comparison of extensive and normal-form behavior is about whether two conceptually equivalent ways of presenting a game lead to different behavior. The issue of role reversal is also close to our main focus, since it is a procedure that yields more information and also may facilitate subjects' comprehension of the situation. The issue of whether decisions are presented individually or in group is also related to our main focus, since in the direct-response method you make decisions in isolation, while in the strategy method you make all the potentially relevant decisions jointly. 
An elicitation issue that is quite important to experimental design is the issue of whether people react differently to a game presented in extensive form or normal form. While in principle these are usually considered to be equivalent, there may very well be presentation effects. Schotter et al. (1994) investigate this issue using three different experimental games presented in either matrix or tree form. They find a strong presentation effect in a simple two-stage game with a secure strategy for one player and an incredible threat for the other player. People are much more likely to use (or to fear) incredible threats when the game is presented in matrix form. However, the presentation effect either vanishes or is considerably attenuated in more complex second and third games involving three stages and either mixed strategies or forward induction. $^{29}$

Cooper and Van Huyck (2003) examine a series of $2 \times 2$ games in either normal or extensive form. In the extensive form representation, there is a systematic (although modest) shift by first players toward the option that allows the second players to make a move; the play of second movers is unaffected. One interpretation of this pattern is that some fraction of the population has a preference for inclusion-all else being equal, they like others to have a say in the outcome. For this preference for inclusion to apply, one must believe that one's choice plays a role in whether the other player has a say. The treatment effect is then due to framing, as preferences for inclusion are more salient in the extensive-form game, leading to the shift toward letting the second mover have a play in the tree version of the game. ${ }^{30}$

Role reversal is an approach in which the participants play more than one role. While this device is used in experiments with multiple periods, and is thought to potentially facilitate learning by requiring people to see the game "from both sides", here we are primarily concerned with the case where each person plays a game twice, but in different roles. Brosig et al. (2003) point out: "If subjects not only think about what they would do if they were in the role of their opponent, but are in addition aware that they will subsequently be given that opportunity, they are likely to undertake greater self-reflection right from the beginning." One might also think that people see role reversal as suggesting that the two players take turns being selfish, as suggested in the "reduced responsibility hypothesis" in Burks et al. (2003). This is clearly an empirical matter.

While role reversal in otherwise one-shot games has been used in a fair number of papers, there has been only a modest amount of systematic study of its effects on behavior. Güth and Tietz (1990) survey ultimatum-game experiments and conclude that people who play both roles make smaller demands; however, Carter and Irons (1991) and Weg and Smith (1993) find the opposite result (in comparison with the result without role reversal in Forsythe et al. 1994). Snijders and Keren (1999) find more trust and trustworthiness when participants play both roles in a trust game, compared to behavior in Güth et al. (1997). In one treatment of a trust game, Burks et al. (2003) tell first movers that they will be playing both roles before they make their initial decisions, while in another treatment first movers were only told this after making their

\footnotetext{
${ }^{29}$ Rapoport (1997) looks at the related issue of timing in games, and finds a significant order-of-play effect in a game involving dilemmas with uncertain resources, a game involving public goods, and a three-player coordination game.

${ }^{30}$ This interpretation is taken from personal communication with David Cooper.
} 
initial decisions. They find strong evidence that playing both roles decreases trust and trustworthiness. Finally, Charness and Rabin (2005) replicate without role reversal many of the games explored with role reversal in Charness and Rabin (2002); they find little effect from role reversal, as none of the 18 available comparisons shows a difference significant at the 5\% level. Overall, it is difficult to draw any conclusion from these studies about the effect of role reversal. ${ }^{31}$

A final presentation issue concerns whether decisions are presented individually or in groups. Blount and Bazerman (1996) conducted experiments with a \$10 ultimatum game. The experimental manipulation was the specific manner in which the minimum acceptable amount was elicited for choosers. In one condition the responder was asked to decide what the smallest amount that he or she would accept from the proposer, while in the other condition, responders were given a series of choices concerning specific offers (although these offers were only hypothetical). They find that people are less concerned with fairness when simultaneously choosing between two outcomes than when considering each outcome separately. The median (mean) minimal acceptable amount was $\$ 5.00$ (\$4.00) in the minimum acceptable payoff, compared to $\$ 2.50$ (\$2.33) in the choice condition ( $p<0.001$ in each case). While this is not precisely the strategy method versus the direct-response method, it does indicate that behavior is sensitive to the elicitation method.

\section{Summary and conclusion}

As is to be expected from a survey of empirical comparisons, there are studies that find a difference and studies that do not. There are more studies that find no difference than studies that find one. The next question that arises is whether there is some commonality between the studies that do find a difference and those studies that don't. In our survey we consider potentially-relevant dimensions and test for differences along these dimensions. However, we must caution the reader that the amount of data in each category makes it difficult to confidently make inferences. First, in environments involving emotional behavior, we do not find differences between the two elicitation methods. We do find, however, that a particular aspect of emotions-related behavior, the use of punishment, is significantly more likely in situations with direct response than with strategy choice. Second, we find some indication that situations involving a lower number of decisions lead to more differences in behavior than situations with more decisions.

A final issue to consider is the possibility that publishing bias may have influenced the available data set. It seems plausible that studies that from the outset aim at investigating a difference between methods may be more likely to be published if they find an effect. At the same time, the reverse may be true for studies with quite different

\footnotetext{
${ }^{31} \mathrm{~A}$ related (and less explored) issue is the role of role uncertainty. Iriberri and Rey-Biel (2008) test whether people make different dictator choices when they know if they will be the dictator and when they don't know before making their choices (making comparisons with the same games with role uncertainty in Charness and Grosskopf 2001 and in Engelmann and Strobel 2004). They find clear evidence that selfish behavior is more common when one knows one will be the dictator, while social-welfare-maximizing behavior is more common when one does not know one will be the dictator.
} 
motivations that include comparison treatments with the two elicitation methods as a way of testing for robustness. However, at this point there is simply not enough information to discuss this issue in a meaningful way.

In summary, while we do not claim that our study is definitive, it should at least dispel the impression that the strategy method inevitably yields results that differ significantly from results gathered using the traditional direct-response method. More research is needed to provide even more definitive evidence on this very pertinent issue in experimental economics.

Acknowledgements We would like to thank Klaus Abbink, Nick Bardsley, Steve Burks, David Cooper, Tim Cason, Armin Falk, Ernst Fehr, Werner Güth, Nagore Iriberri, Rosemarie Nagel, Theo Offerman, Amnon Rapoport, Pedro Rey-Biel, Chris Snijders, Sara Solnick and Fangfang Tan for encouragement and helpful comments, as well as the many authors who were kind enough to send us their papers. Financial support from the Spanish Ministerio de Ciencia e Innovación, the Barcelona GSE Research Support Program and Consolider-Ingenio is gratefully acknowledged.

Open Access This article is distributed under the terms of the Creative Commons Attribution Noncommercial License which permits any noncommercial use, distribution, and reproduction in any medium, provided the original author(s) and source are credited.

\section{Appendix}

Table 2 Sub-categories and experimental findings

\begin{tabular}{|c|c|c|c|c|c|}
\hline Experiment(s) & Difference? & \# of choices & $\begin{array}{l}\text { Multiple } \\
\text { periods? }\end{array}$ & Punishment & $\begin{array}{l}\text { Revised } \\
\text { choices? }\end{array}$ \\
\hline Armentier (2004) & No & 1 & Yes & No & Yes \\
\hline $\begin{array}{l}\text { Armentier and Treich (2007), } \\
\text { Goeree et al. (2002) }\end{array}$ & No & 6 & Yes & No & No \\
\hline $\begin{array}{l}\text { Bosch-Domènech and } \\
\text { Silvestre }(1999,2006)\end{array}$ & No & 8 or 11 & No & No & Yes \\
\hline Brandts and Charness (2000) & No & 2 & No & No & No \\
\hline Brandts and Charness (2003) & Yes & 2 & No & Yes & No \\
\hline Brandts et al. (2009) & No & 2 & Yes & No & No \\
\hline Brosig et al. (2003) & Yes & 2 & No & Yes & No \\
\hline Büchner et al. (2007) & No & 2 & No & No & No \\
\hline Casari and Cason (2009) & Yes & 2 & No & No & No \\
\hline Cason and Mui (1998) & No & 21 & No & No & No \\
\hline Cox and Hall (2010) & Mixed & 11 & No & No & No \\
\hline Falk et al. (2005) & Mixed & 4 & No & Yes & No \\
\hline Falk and Kosfeld (2006) & No & 1 & No & No & No \\
\hline $\begin{array}{l}\text { Fischbacher and Gächter } \\
(2006)\end{array}$ & No & 21 & No & No & No \\
\hline Fong et al. (2007) & No & 3 & No & No & Yes \\
\hline Güth et al. (2001) & Mixed & 2 & No & Yes & No \\
\hline Hommes et al. (2005) & No & 1 & Yes & No & Yes \\
\hline
\end{tabular}


Table 2 (Continued)

\begin{tabular}{llclll}
\hline Experiment(s) & Difference? & \# of choices & $\begin{array}{l}\text { Multiple } \\
\text { periods? }\end{array}$ & Punishment & $\begin{array}{l}\text { Revised } \\
\text { choices? }\end{array}$ \\
\hline Kübler and Müller (2002) & Mixed & 10 & Yes & No & No \\
Meidinger et al. (1999) & Mixed & 11 & No & No & No \\
$\begin{array}{l}\text { Mitzkewitz and Nagel (1993), } \\
\text { Rapoport and Sundali (1996), }\end{array}$ & No & 13 & Yes & No & No \\
Rapoport et al. (1996) & & & & & \\
Muller et al. (2008) & No & 4 & Yes & No & No \\
Murphy et al. (2006, 2007) & Yes & 1 & Yes & No & No \\
Offerman et al. (2001) & Mixed & 1 & Yes & No & Yes \\
Oxoby and McLeish (2004) & Mixed & 1 & No & Yes & No \\
Rapoport and Fuller (1995) & Mixed & 25 & Yes & No & No \\
Reuben and Suetens (2008) & No & 4 & Yes & No & No \\
$\begin{array}{l}\text { Seale and Rapoport (2000), } \\
\text { Sundali et al. (1995), Rapoport }\end{array}$ & Mixed & 10 & Yes & No & No \\
et al. (1998) & & & & & \\
Solnick (2007) & No & 11 & No & No & No \\
Sonnemans (2000) & No & 1 & Yes & No & Yes \\
\hline
\end{tabular}

\section{References}

Abbink, K., Irlenbusch, B., \& Renner, E. (2000). An experimental study of reciprocity and retribution. Journal of Economic Behavior and Organization, 42, 265-277.

Armentier, O. (2004). Do wealth differences affect fairness considerations? Université de Montréal, mimeo.

Armentier, O., \& Treich, N. (2007). Subjective probabilities in games: an application to the overbidding puzzle. Université de Montréal, mimeo.

Axelrod, R. (1984). The evolution of cooperation. New York: Basic.

Bardsley, N., Cubitt, R., Loomes, G., Moffatt, P., Starmer, C., \& Sugden, R. (2010). Experimental economics: rethinking the rules. Princeton: Princeton University Press.

Blount, S., \& Bazerman, M. (1996). The inconsistent evaluation of absolute versus comparative payoffs in labor supply and bargaining. Journal of Economic Behavior and Organization, 30, 227-240.

Bosch-Domènech, A., \& Silvestre, J. (1999). Does risk aversion or attraction depend on income? An experiment. Economics Letters, 65, 265-273.

Bosch-Domènech, A., \& Silvestre, J. (2006). Risk aversion and embedding bias. Universitat Pompeu Fabra, mimeo.

Brandts, J., \& Charness, G. (2000). Hot vs. cold: sequential responses in simple experimental games. Experimental Economics, 2, 227-238.

Brandts, J., \& Charness, G. (2003). Truth or consequences: an experiment. Management Science, 49, 116130.

Brandts, J., \& Charness, G. (2009). The strategy versus the direct-response method: a survey of experimental comparisons. Working paper.

Brandts, J., Riedl, A., \& van Winden, F. (2009). Competitive rivalry, social disposition and subjective well-being: an experiment. Journal of Public Economics, 93, 1158-1167.

Brosig, J., Weimann, J., \& Yang, C.-L. (2003). The hot versus cold effect in a simple bargaining experiment. Experimental Economics, 6, 75-90.

Büchner, S., Coricelli, G., \& Greiner, B. (2007). Self-centered and other-regarding behavior in the solidarity game. Journal of Economic Behavior and Organization, 62, 293-303.

Burks, S., Carpenter, J., \& Verhoogen, E. (2003). Playing both roles in the trust game. Journal of Economic Behavior and Organization, 51, 195-216. 
Casari, M., \& Cason, T. (2009). The strategy method lowers measured trustworthy behavior. Economics Letters, 103, 157-159.

Cason, T., \& Mui, V.-L. (1998). Social influence in the sequential dictator game. Journal of Mathematical Psychology, 42, 248-265.

Carter, J., \& Irons, M. (1991). Are economists different, and if so, why? Journal of Economic Perspectives, 5, 171-177.

Charness, G., \& Grosskopf, B. (2001). Relative payoffs and happiness: an experimental study. Journal of Economic Behavior and Organization, 45, 301-328.

Charness, G., \& Rabin, M. (2002). Understanding social preferences with simple tests. Quarterly Journal of Economics, 117, 817-868.

Charness, G., \& Rabin, M. (2005). Expressed preferences and behavior in experimental games. Games and Economic Behavior, 53, 151-169.

Cooper, D., \& Van Huyck, J. (2003). Evidence on the equivalence of the strategic and extensive form representation of games. Journal of Economic Theory, 110, 290-308.

Cox, J., \& Hall, D. (2010). Trust with private and common property: effects of stronger property right entitlements. Games, 1, 527-550.

Engelmann, D., \& Strobel, M. (2004). Inequality aversion, efficiency and maximin preferences in simple distribution experiments. American Economic Review, 94, 857-869.

Falk, A., \& Kosfeld, M. (2006). The hidden costs of control. American Economic Review, 96, 1611-1630.

Falk, A., Fehr, E., \& Fischbacher, U. (2005). Driving forces behind informal sanctions. Econometrica, 73, 2017-2030.

Falk, A., Fehr, E., \& Fischbacher, U. (2008). Testing theories of fairness-intentions matter. Games and Economic Behavior, 62, 287-303.

Fischbacher, U., \& Gächter, S. (2006). Heterogeneous social preferences and the dynamics of free riding in public goods. CeDEx Discussion Paper No. 2006-01.

Fong, Y.-f., Huang, C.-Y., \& Offerman, T. (2007). Guilt-driven reciprocity in a psychological signaling game. University of Amsterdam, mimeo.

Forsythe, R., Horowitz, J., Savin, N., \& Sefton, M. (1994). Fairness in simple bargaining experiments. Games and Economic Behavior, 6, 347-369.

Goeree, J., Holt, C., \& Palfrey, T. (2002). Quantal response equilibrium and overbidding in private-value auctions. Journal of Economic Theory, 104, 247-272.

Güth, W., \& Tietz, R. (1990). Ultimatum bargaining behavior: a survey and comparison of experimental results. Journal of Economic Psychology, 11, 417-449.

Güth, W., Ockenfels, P., \& Wendel, M. (1997). Cooperation based on trust: an experimental investigation. Journal of Economic Psychology, 18, 15-43.

Güth, W., Huck, S., \& Müller, W. (2001). The relevance of equal splits in ultimatum games. Games and Economic Behavior, 37, 161-169.

Harless, D., \& Camerer, C. (1994). The predictive utility of generalized expected utility theories. Econometrica, 62, 1251-1289.

Hommes, C., Sonnemans, J., Tuinstra, J., \& van de Velden, H. (2005). A strategy experiment in dynamic asset pricing. Journal of Economic Dynamics and Control, 29, 823-843.

Iriberri, N., \& Rey-Biel, P. (2008). The role of role uncertainty in modified dictator games. Universitat Pompeu Fabra, mimeo.

Keser, C. (1993). Some results of experimental duopoly markets with demand inertia. Journal of Industrial Economics, 41, 133-151.

Krawczyk, M. (2006). Note on strategy method in experimental games. University of Amsterdam, mimeo.

Kübler, D., \& Müller, W. (2002). Simultaneous and sequential price competition in heterogeneous duopoly markets: experimental evidence. International Journal of Industrial Organization, 20, 1437-1460.

Meidinger, C., Robin, S., \& Ruffieux, B. (1999). Jeu de l'investissement et coordination par les intentions: des résultats expérimentaux. Université Pierre Mendès France, Grenoble, mimeo.

Mitzkewitz, M., \& Nagel, R. (1993). Experimental results on ultimatum games with incomplete information. International Journal of Game Theory, 22, 171-198.

Muller, L., Sefton, M., Steinberg, R., \& Vesterlund, L. (2008). Strategic behavior and learning in repeated voluntary contribution experiments. Journal of Economic Behavior and Organization, 67, 782-793.

Murphy, R., Rapoport, A., \& Parco, J. (2006). Breakdown of cooperation in iterative real-time trust dilemmas. Experimental Economics, 9, 147-166.

Murphy, R., Rapoport, A., \& Parco, J. (2007). Credible signaling in real-time trust dilemmas. University of Arizona, mimeo. 
Offerman, T., Potters, J., \& Verbon, H. (2001). Cooperation in an overlapping generations experiment. Games and Economic Behavior, 36, 264-275.

Oosterbeek, H., Sloof, R., \& van de Kuilen, G. (2004). Cultural differences in ultimatum game experiments: evidence from a meta-analysis. Experimental Economics, 7, 171-188.

Oxoby, R., \& McLeish, K. (2004). Sequential decision and strategy method vectors in ultimatum bargaining: evidence on the strength of other-regarding behavior. Economics Letters, 84, 399-405.

Rapoport, A. (1997). Order of play in strategically equivalent games in extensive form. International Journal of Game Theory, 26, 113-136.

Rapoport, A., \& Fuller, M. (1995). Bidding strategies in a bilateral monopoly with two-sided incomplete information. Journal of Mathematical Psychology, 39, 179-196.

Rapoport, A., \& Sundali, J. (1996). Ultimatums in two-person bargaining with one-sided uncertainty: offer games. International Journal of Game Theory, 25, 475-494.

Rapoport, A., Sundali, J., \& Seale, D. (1996). Ultimatums in two-person bargaining with one-sided uncertainty: demand games. Journal of Economic Behavior and Organization, 30, 173-196.

Rapoport, A., Seale, D., Erev, I., \& Sundali, J. (1998). Equilibrium play in large group market entry games. Management Science, 40, 119-141.

Reuben, E., \& Suetens, S. (2008). Disentangling strategic from non-strategic cooperation in social dilemmas. Mimeo.

Roth, A. (1995). Bargaining experiments. In J. Kagel \& A. Roth (Eds.), Handbook of experimental economics. Princeton: Princeton University Press.

Schotter, A., Weigelt, K., \& Wilson, C. (1994). A laboratory investigation of multiperson rationality and presentation effects. Games and Economic Behavior, 6, 445-468.

Seale, D., \& Rapoport, A. (2000). Elicitation of strategy profiles in large group coordination games. Experimental Economics, 3, 153-179.

Selten, R. (1967). Die Strategiemethode zur Erforschung des eingeschränkt rationalen Verhaltens im Rahmen eines Oligopolexperiments. In H. Sauermann (Ed.), Beiträge zur experimentellen Wirtschaftsforschung (pp. 136-168). Tübingen: Mohr.

Selten, R., \& Ockenfels, A. (1998). An experimental solidarity game. Journal of Economic Behavior and Organization, 34, 517-539.

Selten, R., Mitzkewitz, M., \& Uhlich, G. (1997). Duopoly strategies programmed by experienced players. Econometrica, 65, 517-555.

Selten, R., Abbink, K., Buchta, J., \& Sadrieh, K. (2003). How to play $3 \times 3$-games-a strategy method experiment. Games and Economic Behavior, 45, 19-37.

Snijders, C., \& Keren, G. (1999). Determinants of trust. In D. Budescu, I. Erev, \& R. Zwick (Eds.), Games and human behavior (pp. 355-385). Mahwah: Lawrence Erlbaum.

Solnick, S. (2007). Cash and alternate methods of accounting in an experimental game. Journal of Economic Behavior and Organization, 62, 316-321.

Sonnemans, J. (2000). Decisions and strategies in a sequential search experiment. Journal of Economic Psychology, 21, 91-102.

Sundali, J., Rapoport, A., \& Seale, D. (1995). Coordination in market entry games with symmetric players. Organizational Behavior and Human Decision Processes, 64, 203-218.

Weg, E., \& Smith, V. (1993). On the failure to induce meager offers in ultimatum games. Journal of Economic Psychology, 14, 17-32. 